\title{
SEMBLANZA
}

\section{El liderato político del Presidente Juan Rafael Mora}

Period. Armando Vargas Arayai, Comisión Nacional del Bicentenario Morista Recibido: $16 / 3 / 2015$

Aceptado: 20/04/2015

El camino costarricense fue trazado durante una década fundacional por el empresario Don Juan Rafael Mora, quien a los 35 años resultó electo presidente de la República, a los 42 condujo el país a la Guerra Patria y a los 46 pereció víctima de un crimen de Estado. Vida abreviada y rutilante, sin dudas. En un lapso estrecho logró pasar de empresario principal a primer servidor público y, pronto, ascender a líder de aquel pueblo que contaba apenas con 120.000 habitantes y bregaba por transformarse de comarca en nación.

Líder es palabra derivada del inglés que define a quien es seguido por un grupo que lo reconoce como su jefe o su orientador. Los etimologistas británicos registran en el siglo XIV el término leder aplicado a una cualidad del carácter, que con el sufijo ship -variación de shape, de dar forma- se convierte en leadership, cuyo significado literal es "formar el carácter". En 1821 comienza a hablarse de la posición de leader en un conglomerado humano. A comienzos del siglo XX, leader se traduce como caudillo, el que encabeza un gremio, comunidad o cuerpo; el que guía y manda a la gente de guerra. La lengua española también tiene la voz adalid, procedente del árabe delid, que significa mostrador porque "enseña el camino". En 1726, el Diccionario de Autoridades, origen del Diccionario de la Real Academia Española, recogía esta cita elocuente:

Quatro cosas dixeron los antiguos que deben haver en sí los Adalídes, sabiduría, esfuerzo, buen seso, y lealtád.

"El Presidente Mora fue la personalidad política más importante del siglo XIX en Costa Rica y, puede decirse, en todo Centroamérica", escribió recientemente el catedrático Stephen J. Clark de la California State University, Channel Islands:

Su trascendencia en la historia costarricense quizá pueda ser comprendida más fácilmente por los estadounidenses a través de

i Armando Vargas Araya es periodista, político y escritor, ganador del Premio Nacional de Historia en Costa Rica. Ha tenido a su cargo importantes medios noticiosos y fue Ministro de Comunicación e Información de Costa Rica (1982-1986). Ahora labora como consultor, miembro de la Academia Costarricense de la Lengua y presidente de la Comisión Nacional del Bicentenario Morista.
Armando Vargas Araya. El liderato político del Presidente Juan Rafael Mora. Revista Comunicación. Año 36, vol. 24, núm. 1. Enero - julio, 2015. Tecnológico de Costa Rica. ISSN Impreso: 0379-3974/ e-ISNN: 1659-3820 
una comparación con Abraham Lincoln. Esta analogía puede basarse en los muchos paralelismos entre ambos presidentes, tales como sus modestos orígenes académicos, el rol central desempeñado por ellos en la preservación de sus respectivas repúblicas ante pavorosas amenazas militares, y el hecho de que ambos fueran asesinados poco después de alcanzar sus más grandes triunfos.

Aunque el liderato político es un fenómeno multidimensional de creencias, valores, caracteres, relaciones de poder, principios éticos, actitudes y acciones de los guías y sus seguidores, a los propósitos que nos ocupan conviene acotar su definición en tres aspectos. Uno, el instrumental que es la habilidad para influir en las personas y producir resultados. Dos, el organizativo que permite establecer objetivos y motivar a su consecución. Tres, el estratégico y emprendedor que incluye tanto la creatividad como la adaptación de innovaciones.

En una carta remitida desde Berlín, en 1853, el renombrado naturalista europeo Alejandro de Humboldt destacó "la actividad que Vuestra Excelencia el Presidente Mora despliega en la sabia administración del Estado y su amor al progreso de toda ciencia útil". Es decir, la sensatez y el buen juicio, junto con el avance y perfeccionamiento de la educación, la ciencia y la cultura.

El liderato político es esencial en el progreso de las naciones. Se sabe que un liderazgo débil contribuye al fracaso de los gobiernos y que un liderato fuerte es indispensable para asegurar el éxito. Está comprobado que, a la larga, el liderato esclarecido genera prosperidad, mientras que el liderazgo imprudente acaba, a la corta, en catástrofe. La experiencia demuestra que la falta de liderato hace de la gobernanza una rutina, anula la creatividad política, deviene en un patrón repetitivo.

En un sistema democrático incipiente, el Presidente Mora practicó un liderato dinámico. "El título de jefe de la nación indica que nadie puede ser su colega", afirmó ante el Congreso Nacional en 1853:

No quiero la dictadura y creo sinceramente que se ha hecho hoy día menos necesaria que nunca. Pero, precisamente para que no llegue el caso de reclamarla, será oportuno pediros en breve un ensanche de atribuciones que me permita extender no solo mi vista sino también mi acción a todas las funciones del poder y suplir, cuando sea preciso, la falta de garantías que algunas situaciones puedan presentar en ciertos casos que nuestras leyes no han podido prever.

Justificaba esa aspiración a una autoridad ampliada con este argumento:

¿De qué me serviría hacer prosperar el Estado y extender su nombre en el exterior si una falta de algún alcalde, cubierto con lo que él Ilama su independencia judicial, viniese a comprometer esta prosperidad y esta reputación resultado de tantos desvelos? Tened en cuenta esta consideración y no vacilareis en remediar un mal que puede llegar hasta la ruina de la República.

Tan diáfana profesión de fe presidencialista era provocada por lo que ahora se denomina ingobernabilidad, consecuencia de la falta de objetivos comunes y carencia de armonía en el avance hacia unas metas nacionales. Don Manuel Argüello Mora sobrino de Don Juan Rafael opinaba en 1897 que don Braulio Carrillo, don José $\mathrm{M}^{\mathrm{a}}$ Castro Madriz y otros gobernantes fueron pseudo republicanos, esto es, repúblicos en la forma y soberanos más o menos absolutos en el fondo". Eran épocas de menor desarrollo político en las que se requería mano de hierro en guante de seda para conducir con firmeza el proceso de construcción del andamiaje institucional que conformaría el Estado. Apreciada con el beneficio de una retrospectiva de 161 años, esa doctrina hiperpresidencialista ahora se juzgaría inaceptable pues subordinaba los otros poderes públicos al Ejecutivo.

¿Qué pensaban sus contemporáneos sobre el liderato del Presidente Mora?

A los cuatro años de ejercer el mando, su predecesor alajuelense en la Jefatura de Estado don José María Alfaro escribió a su hijo José Joaquín, quien estudiaba Derecho en Guatemala, que don Juan Rafael era "popular, sagaz, comedido, honrado, enérgico, empresario, ejecutivo y de talento". En diez palabras pintaba ocho aspectos distintivos del liderato que desplegaba el joven estadista:
a. Conocido y estimado por el público en general;
b. Astuto y prudente, preveía y prevenía las cosas;
c. Moderado en el fondo y en las formas; 
d. Íntegro en el obrar, con rectitud de ánimo;

e. Eficaz en el uso del poder;

f. Resuelto al emprender acciones dificultosas o azarosas;

g. No daba espera ni permitía que se difiriera la ejecución de órdenes;

h. Capacidad de entendimiento y aptitud en el desempeño de sus responsabilidades.

Algunas de estas facetas surgían del legado familiar, otras de su formación autodidacta, unas de su experiencia empresarial y las demás del instinto político suyo.

El Presidente Mora fue electo a los cinco años de haberse iniciado el comercio regular del café con Londres, por medio de la línea naviera del capitán William Le Lacheur. El coffee trade era todo un paquete de flujos transnacionales de costumbres, ideas, información, inversión, personas, producción y tecnología que provocó marcada movilidad en el país. Don Juan Rafael había nacido súbdito del Imperio Colonial Español y su vida transcurrió bajo siete banderas distintas. La república había sufrido grave inestabilidad con una decena de jefes de gobierno en los doce años anteriores a su elevación a la silla presidencial. En esa época no se podía pisar suelo firme sino que la élite intelectual, empresarial o política se mantenía como quién dijera sobre una correa movediza.

Al concluir su primer mandato de tres años, en el cual sustituyó a su antecesor dimitente, el Presidente Mora anunció el propósito de modificar su política en obsequio de las reformas y del progreso. El pueblo costarricense ha adquirido ahora un amor propio nacional que debe estimularle a merecer más el aprecio de las otras naciones. No obstante, supo gobernar con pragmatismo sin convocar una Asamblea Constituyente a los efectos de actualizar la Ley Fundamental.

Don Juan Rafael poseía clara comprensión de la revolución industrial que, desde Inglaterra, esparcía su preponderancia por el globo. "¿Qué?", preguntó a los representantes populares en el Congreso Nacional de 1856:

Cuando el tiempo se acorta y las distancias desaparecen ante la rápida rotación del vapor; cuando el pensamiento humano, no satisfecho con cruzar los aires como el rayo, atraviesa el fondo de los mares con alas de fuego; cuando los idiomas, las costumbres, las leyes, las artes, las ciencias y los productos de todos los pueblos se cambian y esparcen sin cesar por cuantos ámbitos existen conocidos, o se aglomeran en un solo templo como un foco de luz y concordia universal ¿será compatible la existencia de países privados de todos esos conocimientos, de todos esos bienes, de todos esos prodigios, permaneciendo desterrados por más tiempo de ese inmenso conjunto de grandeza, de ventura y confraternidad?

Su pensamiento abría el surco de "La Vía Costarricen$\mathrm{se}^{\prime \prime}$ por la cual las generaciones futuras pudiesen ascender a etapas de prosperidad general y bienestar público.

Nadie vive fuera de su época y el Presidente Mora fue, a cabalidad, un hombre de su tiempo. Llegó al mando con su agudeza de hombre de negocios cuando (la plutocracia reinaba en Costa Rica), según testimonio del economista Moritz Wagner y el lingüista Carl Scherzer. En 1848 había cosechado 7000 quintales en su hacienda cafetalera de Pavas, y exportó a Europa junto con un socio 30000 sacos del grano de oro. Había hecho en barcos de vela numerosos viajes comerciales y de observación política a Francia e Inglaterra, Estados Unidos y Jamaica, Colombia o Ecuador, Chile y Perú, donde estableció relaciones con personas importantes; en Sudamérica entró en contacto con el pensamiento de intelectuales como Andrés Bello o Domingo Faustino Sarmiento.

Su estatura era de escaso metro con sesenta. Grueso de contextura, relleno el rostro y el cuello corto. Cabello negro peinado hacia atrás y espesa sotabarba. Piel aceituna, ligeramente morena. Frente despejada, de clara inteligencia. Cejas largas, mirada penetrante. Labio superior delgado, nariz romana. Caminaba firme, llevaba bastón con empuñadura de marfil. Hablaba suave y directo. Dormía temprano, madrugaba y hacía siesta. Católico, iba a misa. De maneras refinadas, vestía a la francesa con zapatos de charol y, en ocasiones solemnes, usaba un sencillo frac negro. Prefería pluma, tinta y papel ingleses.

Afable por naturaleza, su fisonomía plácida expresaba más bondad que energía. Por el comercio minorista y el juego de gallos, conocía a fondo la psicología de sus compatriotas. Había servido a muchos y había contribuido a que algunos pobres se hicieran ricos. Por afecto, muchos lo llaman Don Juanito y, en el santuario del hogar, Tatica. Administraba parejo el auge o el infortunio. Era frugal e ilustrado. Obsesivo en la consecución de sus metas. No fue sanguinario ni cruel. Creía 
en el equilibrio entre personas e intereses. Como todo gobernante, era proclive al halago palaciego.

Conservador moderado, la Presidencia de la República vino a quedarle como una extensión de sus quehaceres particulares. Consideraba que el gobierno tiene dotes de "padre del pueblo", que debe vigilar constantemente por el bienestar general de la familia costarricense que le está encomendada, sin atender a otras consideraciones que a las de su conservación, que es la primera de las leyes. Creía que sin maíz no hay país y fijó por decretó su precio, así como el de los frijoles y las papas.

Había heredado de sus mayores la acción política como una responsabilidad social. Su bisabuelo, Camilo Mora Sánchez de Estrada, ostentó el título de capitán a mediados del siglo XVIII en Cartago. Su abuelo, José Dionisio Mora Valverde, se desempeñó como juez de los campos, autoridad rural que enjuiciaba y castigaba a quienes cometen delitos en despoblado. Su padre, el hombre de negocios Camilo Mora Alvarado, fungió como alcalde de San José, promovió la enseñanza pública y la libertad de escritura. Don Juan Rafael descubrió los arcanos de la titularidad del mando por medio de su primo segundo y prócer de la Independencia Nacional, Juan Mora Fernández, jefe de Estado durante nueve años consecutivos, además de diputado constituyente y magistrado en la Corte de Justicia. Ciertamente, el Presidente Mora fue un líder político de casta. El liderato político exige como condición indispensable la existencia de seguidores. Y don Juan Rafael gozó de una simpatía extraordinaria entre sus compatriotas. No existían entonces partidos políticos, ni campañas electorales. La titularidad del mando se disputaba entre un puñado de hombres de unas veinte familias principales. Los comicios eran de segundo grado, a la manera de algunas democracias como Estados Unidos todavía hoy. Los vecinos varones, mayores de edad, propietarios alfabetizados, se reunían y nombraban electores que, a su vez, votaban por los candidatos; en 1849 sufragaron 90 electores. En aquel sistema imperfecto para el criterio actual, el Presidente Mora construyó y mantuvo un caudal de seguidores. El intelectual guatemalteco Lorenzo Montúfar escribió que la bondad de su corazón y el deseo del bien de su patria, le produjeron una popularidad que no se había visto hasta entonces en Costa Rica.

Era aquel un país pobre que comenzaba a percibir los beneficios de la civilización, especialmente como resultado del coffee trade con Londres. La mayoría era analfabeta aún, aunque funcionaban 71 centros educativos con 3500 alumnos y un centenar de estudiantes en la Universidad de Santo Tomás. En 1835 llegó el primer piano y a los catorce años había más de 30 en la ciudad capital, algunos de cola. En poco tiempo abrió sus puertas el Teatro Mora y se planeó organizar un jardín botánico y un museo nacional. El correo de Europa se recibía dos veces al mes y circulaban dos periódicos, La Gaceta y Eco del Irazú. Las cosechas agrícolas y las fiestas religiosas dominaban el calendario anual. Los viajeros Scherzer y Wagner apuntaron su impresión de que la gente hablaba sobre todo de comidillas de vecindario, las peleas de gallos, el precio del café, el teatro, los bailes y el clima. Era notable el trato respetuoso entre las personas: maestros y padres trataban de usted a los niños de siete años, que usaban la fórmula de cortesía "hágame el favor". La tolerancia echaba raíz pues había una congregación y un cementerio protestantes en una sociedad muy católica. La frugalidad y la moderación eran características generales, junto con la honradez y la fidelidad.

El comercio era la actividad económica más importante con una feria semanal en la plaza mayor. En aquel tiempo se vivía el boom del café. Las fortunas se contaban por decenas de millares de pesos, cuando en Venezuela eran de centenares de miles y en México de millones de pesos. La pobreza extrema era escasa pero casi todos andaban descalzos. Los ingresos fiscales ascendieron en 1850 a 340099 pesos (en el anterior año habían llegado a 232 733), mientras que los egresos sumaron 314701 pesos (en el ejercicio anterior habían sido de 243 002); para el año siguiente se presupuestaron ingresos por 323030 pesos y egresos por 317199. Los visitantes europeos se sorprendían al llegar a los valles altos en el centro del país, "con sus haciendas, potreros, cafetales y bananales se extendía como un inmenso jardín del paraíso, de un verdor brillante". El caballo y las carretas tiradas por bueyes eran los medios de transporte. Las casas eran de una sola planta, oscuras y húmedas; solamente unas cuantas tenían segundo piso y vidrieras. Los muebles eran sencillos, muy pocos espejos, apenas lo indispensable. La catedral, el Palacio Nacional, el Cuartel Principal, las Fábrica Nacional de Licores y la Universidad de Santo Tomás Ilegaron a caracterizar el perfil urbano de la capital.

Al Presidente Mora le correspondió ejercer el liderato político en una sociedad pequeña y pobre, con un Estado en proceso formación, sin normas legales e instituciones políticas adecuadas, una economía agroexportadora en crecimiento, enormes necesidades de infraestructura y, como se verá adelante, con amenazas militares externas que llegaron a poner en riesgo la existencia de la República. 
Los más de los costarricenses vivían aislados del mundo, entre las montañas que rodean los valles del Guarco y el Virilla. El líder político tuvo la misión de explicitar una agenda de problemas comunes y proponer las soluciones posibles. Declaraba su convicción de que "solo han podido subsistir y hacer positivos bienes a sus pueblos los gobiernos fuertes, basados en ideas de orden y rectitud".

Ciertamente no todos sus contemporáneos estaban de acuerdo con su visión sobre el porvenir de la patria. En sus informes anuales al Congreso Nacional se aprecia el elenco de las preocupaciones del gobernante, sintetizadas así:

a. Sostener el respeto debido al Gobierno y las leyes de la república sin mengua del honor nacional;

b. Sostener el orden público sin temor ni consideraciones de ninguna especie.

c. Defender la integridad del territorio, la soberanía e independencia de la nación.

d. Proteger la educación, el comercio, la agricultura y las artes con todos los medios de que puede disponer el Gobierno.

e. Emplear para con todas las naciones una política franca, leal, moderada y respetuosa.

El propósito del Presidente Mora era que con fundamento sólido en la tranquilidad interior y la seguridad exterior se expandiera:

Al amparo de un progreso benevolente, Costa Rica era un pueblo en marcha hacia un horizonte superior de abundancia, equidad y dicha. El avance institucional, el dinamismo económico y la conducción acertada hacían posible que el líder político impulsara una avanzada visión ética del desarrollo centrado en la persona humana, consustancial a la concordia de la solidaridad como valor fundante de la costarriqueñidad, cuando en Francia comenzaba a hablarse por entonces del Étatprovidence o Estado social.

El liderato político del Presidente Mora sobrepasó con creces la prueba definitiva que constituyó el desafío del expansionismo esclavista y el triunfo sobre la invasión armada procedente de Estados Unidos. Su dirección política, diplomática y militar de la Guerra Patria es una montaña de granito de cuyas canteras se pueden extraer y cincelar abundantes lecciones destinadas a vigorizar el carácter costarricense. Baste men- cionar únicamente dos elementos emanados de sus proclamas bélicas. En la primera alocución no solo advierte de la amenaza que se cierne sobre el país sino que, con singular maestría, define la esencia de la identidad nacional o personalidad común que podría sucumbir si se impusiera la agresión armada. En la segunda proclama, dilata el peligro de la agresión filibustero al continente todo puesto que va a luchar también por la independencia de Hispanoamérica y de la humanidad entera visto que se va a enfrentar nada menos que la esclavitud del hombre por el hombre. Una de las tareas del líder político consiste en interpretar para sus seguidores el significado de los acontecimientos y su proyección geográfica e histórica.

¿Cuáles fueron los recursos utilizados por el Presidente Mora en la forja y el ejercicio de su liderato político? Usó, claro está, la autoridad inherente a su cargo y los dineros del fisco pero su impronta se afirmó sobre todo por apoyarse en forma inteligente sobre los recursos de índole intangible. En primer lugar, sus reconocidos logros como hombre de empresa: "Mis actos pasados son garantes de mi conducta futura", dijo en 1853. La coherencia entre su pensamiento y su acción le granjeó la confianza de los seguidores. En segundo lugar, la interacción fluida con los distintos estratos de la ciudadanía: "Mi conducta política se halla justificada por las simpatías populares", explicaba él.

En tercer lugar, la integridad de su compromiso en la Guerra Patria que convocó y encabezó personalmente en la primera campaña. Cuando faltaba financiamiento para reemprender el esfuerzo bélico, fue retado por un millonario: "¿Con qué fondos contaría usted para la guerra?", a lo que respondió: "Con mi capital primero, y en seguida con el de usted". Sus adversarios lo criticaron por haber dirigido el combate de Rivas sin tener estudios académicos en el arte de la guerra, pero el militar guatemalteco Marco Antonio Soto Valenzuela juzgó que el gobernante, "que nunca había sido militar, empleó su sentido común y su concepto de la responsabilidad, mejor que todos los generales que lo rodeaban"; y el obispo e historiador Víctor Manuel Sanabria concluyó: "Fue un héroe. En Rivas se batió como un león".

En cuarto lugar su visión de país que elevó las aspiraciones y la mirada de sus contemporáneos.

En quinto lugar, sin ser un escritor, utilizó la palabra para marcar el rumbo y fijar posiciones hacia la posteridad. 
Transcurridos 154 años desde su asesinato en un crimen de Estado, ¿qué permanece del liderato político morista? En primer lugar, Costa Rica conquistó su segunda independencia nacional en la Guerra Patria contra los designios perversos del expansionismo esclavista procedente de Estados Unidos. Esa gesta no habría sucedido sin la perspectiva anchurosa y la determinación acerada de don Juan Rafael. Claro, mantener incólume la autonomía nacional es una lucha cotidiana. En segundo lugar, el aperturismo globalizador de aquel empresario devenido en estadista se consolidó en el tiempo como estrategia nacional de inserción económica en los mercados internacionales. Con altibajos atribuibles a circunstancias externas, su visión del rol de Costa Rica en el mundo se ha desarrollado en vertientes diversas. Sus metas de progreso se cumplieron todas y se convirtieron en el basamento para el avance nacional. En tercer lugar, el Presidente Mora desató un movimiento continental de identidad. Mora es el pedestal en que se asienta nuestra idea de nación pues el simbolismo de su palabra reverbera en el Himno Nacional; en efecto, cuando Billo Zeledón lo escribió en 1903, se encontró con su interpretación de nuestra personalidad común: el canto nacional es una reconstrucción del poder revelador de su proclama dirigida al pueblo en noviembre de 1855. En cuarto lugar, la presidencia temporal que ejerce Costa Rica de la Comunidad de Estados de América Latina y el Caribe (CELAC), se arraiga en la visión continental que impulsó el Presidente Mora. En quinto lugar, como resultado del empuje de la organización cívica La Tertulia del 56, sus logros y su ejemplo han sido reconocidos por el Estado: en el 2010 la Asamblea Legislativa lo proclamó Libertador y Héroe Nacional y el 2014 se declaró el año del Bicentenario Morista; además, el Consejo Superior de Educación denominó el curso lectivo 2014 "Año Escolar Libertador Juan Rafael Mora" para que escuelas y colegios realicen -como parte de las tareas educativas-actividades especiales de reflexión y homenaje al Presidente Mora.

El recordado catedrático de sociología política Rodolfo Cerdas solía decir que Pablo Neruda escribió un poema en el cual dice que la tierra "se llama Juan", en Costa Rica, gracias a su jefatura y las glorias del 56, el pueblo "se llama Mora". 